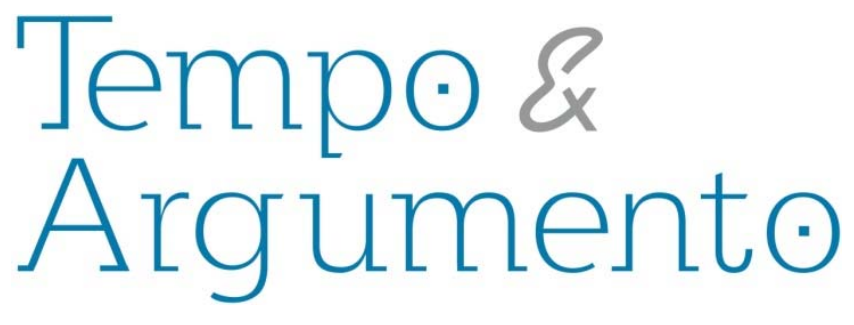

\title{
La guerrilla argentina y las masas: el ERP y su inserción
}

\begin{abstract}
Resumen
Entre 1959 y 1977, se contabilizan más de 17 organizaciones armadas en la Argentina. Más allá del éxito logrado, todas ellas se plantearon una combinación de lucha armada con movilización popular. Para lograr esto, intentaron desarrollar lo que denominaron "trabajo de masas". Dos de ellas, Montoneros y PRTERP, fueron bastante exitosas en lograr la "inserción" de la organización entre la población en general. Aquí, se desarrolla la inserción de la segunda de estas dos organizaciones y se postula que el tema guerrillero, en Argentina, fue mucho más complejo de lo que suponemos. De hecho, la relación entre guerrilla y organización popular plantea que la lucha armada fue producto de un proceso histórico y de reivindicaciones sociales, y no un mero hecho coyuntural.
\end{abstract}

Palabras clave: Argentina; Guerrilla; Movilización; Masas.

\section{Pablo A. Pozzi}

Profesor del Doctorado en Historia y Director de la Maestría en Estudios Culturales de América Latina en la Universidad de Buenos Aires. Argentina. pablo.pozzi@yahoo.com.ar

\section{Para citar este artículo:}

POZZI, Pablo A. La guerrilla argentina y las masas: el ERP y su inserción. Tempo e Argumento, Florianópolis, v. 7, n.16, p. 108 - 128. set./dez. 2015. 


\section{Argentinian guerilla and
masses: the ERP and its \\ Argentinian guerilla and
masses: the ERP and its insertion}

\begin{abstract}
Between 1959 and 1977, there were more than 17 armed organizations in Argentina. Beyond their success, all of them outlined a combination of armed conflict and popular mobilization. To achieve this, they tried to develop the so-called "mass work." Two of them, Montoneros and PRT-ERP, were quite successful in "inserting" the organization among the general population. Herein, the insertion of the second of these organizations is worked up and it is posited that guerrilla as a theme, in Argentina, has been much more complex than we have assumed it to be. In fact, the relationship between guerrilla and popular organization suggests that armed conflict was the result of a historical process and social claims, and not a mere conjunctural fact.
\end{abstract}

Keywords: Argentina; Guerrilla; Mobilization; Masses.

\section{A guerrilha argentina e as massas: o ERP e sua inserção}

\begin{abstract}
Resumo
Entre 1959 e 1977, são estimadas mais de 17 organizações armadas na Argentina. Acima do êxito alcançado, todas buscaram combinar a luta armada com aà mobilização popular. Para tanto, tentaram desenvolver o que se denominou "trabalho de massas". Duas delas, Montoneros e PRT-ERP, obtiveram muito sucesso na "inserção" da organização entre a população como um todo. Aqui, aborda-se a inserção da segunda dessas duas organizações e postula-se que o tema guerrilheiro, na Argentina, foi muito mais complexo do que se supõe. De fato, a relação entre guerrilha e organização popular sugere que a luta armada foi produto de um processo histórico e de reivindicações sociais, e não um mero fato conjuntural.
\end{abstract}

Palavras-chave: Argentina; Guerrilha; Mobilização; Massas.

El Partido Revolucionario de los Trabajadores (PRT) es conocido por haber dirigido al Ejército Revolucionario del Pueblo (ERP), uno de los principales grupos guerrilleros argentinos entre 1969 y 1977. Sin embargo, no puede ser caracterizado como un foco (por lo menos según la definición clásica de Regís Debray (1967), ya que tenía organismos y trabajo de masas, frentes legales y sindicales, agrupaciones estudiantiles y publicaciones. De hecho, el PRT-ERP tuvo éxito en organizar a los trabajadores azucareros 
tradicionalmente peronistas de Tucumán y Jujuy, así como a los hacheros de la empobrecida y conservadora provincia de Santiago del Estero, a los estudiantes y obreros de la católica y anti-peronista provincia de Córdoba, y a los estudiantes izquierdistas de la Universidad Nacional de Rosario. Aunque nunca fueron más que algunos miles de militantes durante la década, el PRT fue influyente en la cultura política del eje TucumánCórdoba-Rosario. Según diversas fuentes, hacia 1975, el PRT tenía células en más de cuatrocientas de las principales fábricas del Gran Buenos Aires; se mantenía fuerte en Tucumán, Jujuy y Santiago del Estero; tuvo éxito en organizar grupos de los obreros industriales cordobeses, de los metalúrgicos, obreros de la carne y petroquímicos de Rosario; y de los petroleros patagónicos. Además, tenía grupos muy activos en el movimiento estudiantil, entre los arrendatarios algodoneros del Chaco, y entre los judiciales y docentes formoseños. Por último, había logrado establecerse en muchas ciudades del interior, tales como Río Cuarto, Rafaela, Ceres, San Francisco, General Roca, Neuquén, Junín, Mendoza, Metán, Clodomira, Bahía Blanca, Santa Fe y Paraná. En su punto más alto, su periódico clandestino El Combatiente tiraba 20.000 ejemplares; tenía además publicaciones dirigidas a sectores obreros específicos'; y tres publicaciones legales, el diario El Mundo, el semanario Nuevo Hombre y la revista política Posición. A pesar de todo esto, uno de los temas centrales a considerar -sobre todo por la aniquilación de la organización hacia 1977- es ¿cuán profunda fue su inserción entre las masas argentinas?

El tema de la relación entre una organización y las masas es uno de los más complejos a discutir. En general, a esto se le llama el grado de inserción en tal o cual sector social. Una gran parte de la problemática reside en la definición de lo que implica "la inserción". Otro problema tiene que ver con la diferencia de perspectiva entre los observadores y los objetivos de la misma organización. En este sentido, criticar una organización estudiantil por no tener inserción entre sectores obreros no tiene sentido. Así, es distinta la ponderación de la inserción de un partido revolucionario, clandestino y de cuadros, al de uno legal, populista y de masas. Pero aún más complejo es considerar los elementos de juicio que permitan caracterizar el grado de inserción de una

\footnotetext{
${ }^{1}$ Por ejemplo, El Combatiente Telefónico y El Combatiente Metalúrgico.
} 
organización. Si una organización capta obreros, ¿esto significa que tiene una buena inserción entre los trabajadores? A su vez, si conduce un sindicato, o si se pudiera comprobar que cuenta con la simpatía de algún sector de la población, ¿qué nos dice esto sobre su inserción?

En este caso -el del PRT-ERP, partido revolucionario, clandestino y de cuadrosdefinimos inserción como la capacidad que tiene una organización para representar demandas populares, para desarrollarse entre las masas, ser referente y poder orientarlas. Como toda definición, esta es subjetiva, sin embargo a lo que apunta es a precisar la existencia de una relación estrecha entre la calidad y el éxito de un trabajo de masas determinado y el tipo de inserción que logra una organización. El crecimiento en la cantidad de militantes de una organización implica un resultado concreto del trabajo de masas y una mejora en la inserción, pero no es lo único. Un trabajo de masas exitoso no sólo tiene como resultado la captación de nuevos militantes, sino principalmente aumenta su prestigio entre la población, genera simpatía y apoyo. Esto último es muy difícil de medir, porque se encuentra en el terreno de la apreciación subjetiva. Además, las posibles características de la inserción lograda varían de un tipo de organización a otra, contrastando aquellas organizaciones que no generan mayor compromiso o riesgo con aquellas sujetas a los avatares de la represión. ${ }^{2}$ De todas maneras, como regla general nos podemos acercar a valorar el nivel de inserción de una organización política si consideramos el crecimiento de la misma, la difusión y recepción de su propaganda, su capacidad para escuchar y dirigir a distintos sectores de masas y la actitud de la gente común hacia la misma.

Esto no implica de ninguna manera que las masas ingresan "al partido" (ni aun cuando este sea “de masas”), sino que existe una relación entre organización y gente que le permite al primero contar con el apoyo informal de los segundos. A su vez, esto debería prevenirnos contra un tipo de idealización por la cual "el pueblo (o la clase) apoya a tal o cual organización". Tanto el pueblo como la clase son un complejo conjunto de

\footnotetext{
2 Es claro que también hay momentos en los cuales la participación política en una organización revolucionaria se convierte en moda o en producto del aventurerismo. Por sus características propias, el ingreso al PRT-ERP fue pocas veces resultado de este tipo de cuestión, si bien hubo aventureros entre sus filas.
} 
individuos, cambiantes según el momento, las presiones, y la conciencia. También debemos prevenirnos sobre la generalización a partir de ejemplos individuales. Sin embargo, tomando en cuenta los necesarios recaudos, lo que si pueden indicar estos ejemplos es que existe un cierto nivel de simpatía (o no $)^{3}$ y ciertos niveles de apoyo informal. A la vez, es poco probable que esta situación se dé uniformemente a través del tiempo y a lo largo de la geografía. En síntesis, el grado de inserción de una organización varía según su política, según el momento histórico y cómo éste es percibido por las masas y, sobre todo, según la calidad de cada militante individual. Es perfectamente factible que un militante con una excelente inserción en Córdoba no logre desarrollarla en Tucumán, o que esta inserción sea buena en el momento de auge de masas y más débil en un momento de reflujo, cuando aumentan los costos de simpatizar con una organización sujeta a la actividad represiva del Estado.

El caso del PRT-ERP es complejo de por sí, tanto por el tipo de organización como por la problemática de recopilar información fehaciente y por el obstáculo de que aun hoy, décadas más tarde, genera pasiones y fuertes discusiones. Debemos recordar que el PRT se planteó en todo momento ser un partido de cuadros y no de masas. ${ }^{4}$ La organización hizo un balance de su propio desarrollo a mediados de 1974. En este momento, estimaba que:

[...] el PRT [...] cuenta hoy en día con una sólida estructura nacional, varios miles de miembros activos, varios centenares de cuadros sólidos, tradición y experiencia de combate [...] Pero nuestro Partido encuentra

3 La "simpatía" es un concepto por demás problemático, poco asible y, sobre todo, escasamente cuantificable. Sin embargo, es el mejor concepto del que disponemos para referirnos a formas informales de apoyo. La complejidad del tema se puede ver con mayor claridad si consideramos que muchas de las acciones del ERP generaban simpatía, pero no se traducían en apoyo político concreto. Por qué esto no ocurría es un tema que merece ser profundizado e investigado. Lo real es que la simpatía es un tipo de apoyo a tomar en cuenta, pero, al mismo tiempo, refleja un contactar con sentires de la población y un escaso desarrollo político. Un ejemplo de esto eran apoyos solidarios con militantes por el mero hecho de que "son jóvenes voluntariosos", sin distinción de la organización a la que pertenecían y la línea política que sustentaban. Agradezco a Celina Bonini esta observación.

4 Debería quedar claro que ambos se dirigen a "las masas" y aspiran a dirigirlas. La diferencia entre un tipo y otro de organización tiene que ver con la estructura que se desarrolla. Un partido "de cuadros" implica que todos sus miembros pertenecen a alguna de sus estructuras y activan regularmente. En este sentido, son "profesionales de la revolución". En cambio, un partido "de masas" organiza a sus adherentes en militantes (aquellos que activan) y afiliados. El primero es un partido de calidad que se centra en la guerra de clases, mientras que el segundo se acerca más al esquema de los partidos electorales. Es evidente que ambos aspiran no sólo a dirigir las masas, sino también a incorporarlas a la organización. 
aún grandes dificultades para cumplimentar eficazmente su labor revolucionaria. Ello se debe principalmente a insuficiencias en la penetración orgánica en el proletariado fabril, débil composición social que alcanza a sólo un 30 por ciento de obreros fabriles, insuficiente habilidad profesional en la ejecución de las tareas revolucionarias y limitado número de miembros organizados (SANTUCHO, 1974, 45).

Es por esto que se caracterizaba a sí mismo como "un núcleo del [...] partido proletario de combate", y no como él partido de la revolución. Y, si bien el propio PRTERP estimaba su inserción como insuficiente, habría que analizar hasta dónde había llegado esta inserción, cuáles eran sus características y cuáles sus debilidades. El propio PRT-ERP medía su grado de inserción casi exclusivamente a través de la cantidad de obreros captados. Sin embargo, esto era contradictorio con el hecho que el factor principal para ingresar a la organización era cualitativo y no cuantitativo: las cualidades políticas y humanas del aspirante eran determinantes, junto con la opinión de sus compañeros de trabajo y vecinos. La suposición era que la organización debía tener un crecimiento cualitativo para así poder incidir en el movimiento de masas. La cantidad de militantes no era el único criterio que reflejaba una inserción real. En este sentido, lo importante no era cuántos militantes tenía el PRT en Propulsora Siderúrgica, sino su ubicación socio-política5 ${ }^{5}$ el cómo los percibían los trabajadores y el desarrollo y la penetración de la prensa y propaganda partidaria. Lo fundamental para determinar el grado de inserción es caracterizar la relación entre la organización y las masas.

De los distintos documentos podemos deducir que el principal eje del trabajo de masas del PRT-ERP era la clase obrera industrial, tanto en el lugar de trabajo como en el barrio, y en menor grado sectores marginados o estudiantiles. El trabajo de masas del PRT-ERP era desigual en el nivel nacional. Las distintas rupturas junto con la "desviación militarista" de 1971-72 habían afectado más seriamente a regionales como Rosario, Buenos Aires o La Plata que a Córdoba o Tucumán. Asimismo, el corto período de tolerancia (y no de legalidad) entre mayo y agosto de 1973, también incide en las cifras disponibles. Según una fuente partidaria, durante este período El Combatiente tiraba 21.000 ejemplares, en colores, distribuidos 15.000 en kioskos de diarios y 6.000 trabajados

\footnotetext{
${ }^{5}$ Por ubicación socio-política entendemos el peso político y social específico que puede tener un militante dentro del lugar de trabajo.
} 
por la militancia, mientras que Estrella Roja hacía lo mismo con 54.000 ejemplares, 40.000 en kioskos y 14.000 a través de la militancia (PRT-ERP, 1974, 16). Si bien esta cantidad de ejemplares no quiere decir que la gente común leyera, o coincidiera, con lo que planteaban estas publicaciones, la realidad es que la cantidad de ejemplares tirados y su distribución competían ampliamente con cualquier publicación comercial. ${ }^{6}$ Una vez terminado el período "de tolerancia", la tirada de ambas publicaciones bajó aproximadamente a la mitad. De hecho, disponemos de cifras parciales para la distribución y venta de ambas publicaciones en 1974. El número 39 (26 de agosto de 1974) de Estrella Roja fue distribuido de la siguiente manera: Bahía Blanca (300), Buenos Aires (4.300), Norte-Norte (1.200), Rosario (1.500), Santa Fe (700), Chaco (350), Tucumán (850); para un total parcial de 9.200. Asimismo, las cifras para la distribución del número 130 (14 de agosto de 1974) de El Combatiente fueron: Bahia Blanca (250), Buenos Aires (3.200), Norte-Norte (330), Rosario (1.600), Santa Fe (500), Chaco (300), Tucumán (600); para un total parcial de 6.680 ejemplares.7 Por supuesto, distribución y venta no quiere decir que efectivamente hubiera lectores o que estos compartieran lo que planteaban las publicaciones, pero si quiere decir que estos abonaban el importe reflejando un cierto nivel de apoyo y compromiso. Tampoco podemos saber con exactitud si esta cantidad de prensa era repartida y efectivamente cobrada y discutida con el lector, o simplemente si era volanteada. ${ }^{8}$

\footnotetext{
${ }^{6}$ Las publicaciones del PRT-ERP no eran las únicas con este desarrollo. A partir de 1970 hubo un notable auge de las publicaciones de izquierda. En este sentido, las cifras reflejan más aún el desarrollo del PRTERP, tanto porque el crecimiento de su prensa fue tardío (post 1972) como por el hecho que la sociedad estaba saturada de publicaciones con propuestas y visiones políticas en permanente competencia.

7 Boletín Interno, 66, 20 de agosto de 1974. Nótese que no se citan cifras para regionales como Córdoba, Santiago del Estero o Salta. De incluirse estas zonas es probable que la cifra total aumentara en un 30\%, sobre todo porque Córdoba absorbía una cantidad importante de ejemplares. Por otro lado, algunas de las cifras volcadas deberían ser cuestionadas. Por ejemplo, que Rosario distribuyera más El Combatiente que Estrella Roja es poco probable. Toda la información disponible señala que Estrella Roja era mucho más leído y mejor recibido que el órgano partidario. Asimismo, en el caso de Rosario, donde se distribuía más El Combatiente que Estrella Roja, los testimonios indican que efectivamente se los trabajaba políticamente. Sin embargo, esto también da una indicación de algunos problemas de fondo. Se repartía más El Combatiente porque los lectores lo sentían como "menos peligroso" que Estrella Roja, y por ende menos comprometido. El Boletín Interno, 67, 11 de septiembre de 1974, informa que, desde enero de 1974, la distribución nacional de El Combatiente había aumentado de 6.360 ejemplares a 11.280, mientras que la de Estrella Roja aumentó de 11.400 a 14.330.

8 Según los testimonios que hemos podido recopilar, había regionales donde la prensa era "volanteada", más que distribuida con criterio de trabajo político. El Boletín Interno, 67, 11 de septiembre de 1974, informa que se cobra "en Propaganda nacional alrededor de un $30 \%$ del total".
} 
A partir de esta información, podemos estimar que tanto la inserción como el trabajo de masas del PRT-ERP tuvieron una evolución muy concreta desde su IV Congreso, en 1968, hasta su fin como organización nacional, a fines de 1977. En un principio, desde el momento de la escisión ${ }^{9}$, durante los preparativos para el IV Congreso, con el sector de Nahuel Moreno y hasta 1972, su inserción se puede caracterizar como embrionaria. Es recién a partir de mediados/fines de 1972 que su inserción se puede caracterizar como extendida y creciente, llegando a un pico en las jornadas de julio de 1975, aunque con escasa profundidad. Por último, desde fines de 1975 hasta fines de 1977 se revelan las debilidades de la inserción anterior dado el éxito de la represión en destruir a la organización a partir de eliminar su estructura, cercenar sus nexos con sectores de masas e imponer el terror entre sus simpatizantes.

Desde 1968 hasta fines de 1972, el trabajo de masas y la inserción del PRT-ERP fueron marcados tanto por las luchas internas y escisiones de la organización como por lo que llamó “la desviación militarista”. ${ }^{10}$ La organización era relativamente pequeña, con un elevado porcentaje de cuadros y militantes presos. ${ }^{11}$ Como resultado, si bien regionales como Buenos Aires, La Plata y Rosario sufrieron fuertes retrocesos en el desarrollo y la inserción de la organización, otras, como Córdoba o Tucumán, mantuvieron una inserción embrionaria con tendencia hacia el crecimiento. Sin embargo, para el PRT El Combatiente la escisión tuvo un resultado concreto en cuanto a que una cantidad importante de gente, hasta este momento periférica, se definió por ingresar en la organización. Esta incorporación de nuevos militantes y el desarrollo de los incipientes trabajos de masas se dan a lo largo de 1968 y 1969. En un año se nota un desarrollo, además de La Plata, en zonas como Santiago del Estero, Salta y Santa Fe, aunque seguimos hablando de una

\footnotetext{
${ }^{9}$ A principios de 1968, una serie de diferencias hicieron eclosión en el seno del PRT en la preparación para su IV Congreso partidario. Previo al mismo, se concretó una división entre un sector liderado por Mario Roberto Santucho que se autodenominó PRT-El Combatiente y el liderado por el histórico dirigente trotskista Nahuel Moreno, denominado PRT La Verdad. Cada uno adoptó el nombre de su periódico. En 1970. el PRT El Combatiente devino en el PRT-ERP, mientras que el PRT La Verdad, luego de su fusión con un sector del Partido Socialista, se transformó en el Partido Socialista de los Trabajadores.

10 Luis Mattini caracterizó las consecuencias de esta desviación como (1) caídas entre la cúpula de la organización, pero crecimiento numérico en la base, (2) el retroceso del trabajo de masas en varias regionales, (3) la independencia política de los comités militares del conjunto de la organización, (4) el aumento del verticalismo en la conducción, y (5) la incapacidad de aprovechar la apertura electoral de 1973 (MATTINI, 1990, 115, 117, 118, 123-124).

${ }^{11}$ El Combatiente, 83, 27 de julio de 1973, consigna 117 nombres de presos políticos liberados pertenecientes al PRT-ERP. En 1972, estos debían representar aproximadamente 1/3 de la organización.
} 
de nuevos militantes, pero por otro la organización vuelve a verse paralizada por el internismo. Este se resuelve en 1970, con el V Congreso, pero a costa de nuevas escisiones, si bien no tan numerosas como la del morenismo. ${ }^{12}$ En 1971, hay un nuevo avance, con la incorporación de más militantes, particularmente en Tucumán, Córdoba y Buenos Aires.

Este crecimiento se ve frenado entre mediados de 1971 y mediados de 1972, tanto por las caídas de una parte de la dirección de la organización, como por el énfasis en la actividad militar. Si bien la desviación militarista parece haber afectado en menor grado el trabajo de masas en zonas como Córdoba y Tucumán, en otros lugares, como Rosario, si implicó un abandono de las tareas que se venían realizando. Pero más serio aún fue el hecho de que la prisión de varios de los cuadros más importantes de la dirección del PRTERP, junto con el énfasis en lo militar, implicó una carencia de línea política y una incomprensión del trabajo de masas. Aun así, no hay que poner demasiado énfasis en los problemas derivados de una dirección en la cárcel. La realidad es que, en este período, los cuadros del PRT-ERP, la mayoría con escasa experiencia, estaban buscando las formas más adecuadas de combinar la lucha armada con el trabajo sindical y reivindicativo. De hecho, entre los mismos dirigentes había escasa comprensión de lo que podía ser un desarrollo dialéctico y en general sus orientaciones se reducían a la inserción fabril, el accionar militar, y la construcción de nuevas células partidarias.

A partir de la fuga del penal de Rawson (el 15 de agosto de 1972) y del retorno, unos meses más tarde, de Mario Roberto Santucho al país, el PRT-ERP revirtió la tendencia anterior bajo la consigna "ir hacia las masas". Durante el mismo periodo, el crecimiento de la organización fue notable a través del país, especialmente entre los sectores trabajadores. Las regionales débiles, o casi inexistentes, del período anterior fueron reconstruidas sobre la base de fuertes trabajos de masas, y tanto en Córdoba como Tucumán el PRT-ERP se convirtió en una de las principales organizaciones políticas.

\footnotetext{
12 Las escisiones de 1973, llamadas ERP 22 de agosto y Fracción Roja, fueron relativamente pequeñas, si bien afectaron a las regionales de La Plata y Buenos Aires una vez más.
} 
Esto es aún más notable si consideramos que la organización se vio cada vez más afectada por la represión.

La información disponible nos permite estimar que entre mediados de 1974 y principios de 1975 el PRT-ERP contaba con células en cada una de las principales fábricas de Capital y Gran Buenos Aires. Muchas de estas células fabriles publicaban su propio boletín partidario, como por ejemplo El Combatiente Metalúrgico, en Dalmine-Siderca, y José Luis Castrogiovanni en Eaton. ${ }^{13}$ Además, en Córdoba era una de las principales fuerzas sindicales y contaba con células en Perkins, Grandes Motores Diesel, Fiat Concord y Materfer, Thompson-Ramco, tenía una importante presencia entre los trabajadores de Luz y Fuerza y en la comisión directiva, codirigía el gremio del calzado, y había logrado niveles de organización en todos los hospitales de la ciudad, en gremios como municipales, alimentación y docentes y en muchos barrios. ${ }^{14}$

En la zona de Quilmes, La Plata y Ensenada, el trabajo iniciado en 1973 había rendido sus frutos. En YPF, con 6 mil trabajadores, había 3 células y editaba el boletín fabril El obrero petrolero. En el Astillero Río Santiago existía una escuadra del ERP (autotitulada “Los Chacales”) y una célula de aspirantes del PRT. También había células del PRT en el frigorífico Swift de Berisso, y una célula de la Juventud Guevarista en Petroquímica Sudamericana. Asimismo, había un buen trabajo en Peugeot, mientras que en Rigolleau se dirigía la fábrica. En Propulsora Siderúrgica

[... ] llegó a haber entre cinco y siete compañeros aspirantes y militantes, y muchos simpatizantes centrados principalmente en Sindical. Se sacaba un boletín fabril y se vendían más de cuarenta El Combatiente que se piqueteaba desde adentro en las secciones. Era común encontrar un obrero leyéndolo en su puesto de trabajo como un diario de circulación masiva. Aquí, además de influencia sindical, el Partido tenía influencia política. ¿Cómo decirlo? Había muchos obreros que no eran ni peronistas, ni radicales, ni comunistas, eran del perreté. ${ }^{15}$

En zonas como Villa Constitución, el PRT-ERP era una de las principales fuerzas cuyos miembros se contaban entre el cuerpo de delegados y en la comisión directiva de la

\footnotetext{
${ }^{13}$ El Boletín Interno, 67, 11 de septiembre de 1974, informa que el PRT-ERP tenía 32 boletines fabriles.

14 Según un testimonio, "teníamos tan organizado el barrio que en la misma cuadra había dos casas operativas".

15 Testimonio de Daniel De Santis (La Plata, 28 de agosto de 1999).
} 
seccional de la UOM. Lo mismo se puede decir de los metalúrgicos y del Swift de Rosario. En cambio, en Tucumán, donde según todos los testimonios era más difícil organizar, el PRT-ERP contaba con una fuerte organización tanto en los ingenios azucareros como a nivel de la comisión directiva de la Federación de Obreros y Trabajadores de la Industria Azucarera (FOTIA) y de gremios como el Sindicato de Obreros y Empleados Vitivinícolas y Afines (SOEVA). Además era la principal fuerza en la Universidad Nacional de Tucumán. En Jujuy tenía una fuerte presencia en la comisión directiva del sindicato del Ingenio Ledesma, donde editaban el boletín partidario El Zafrero. En Santiago del Estero, había un buen trabajo entre estudiantes, colectiveros, hacheros y ferroviarios. En Mendoza, su desarrollo fue más tardío y estaba

[...] vinculado al movimiento estudiantil, y al movimiento obrero de la zona alcoholera de Maipú, básicamente, de alimentación en San José de Guaymallén, y la zona alcoholera y petrolera de Luján, donde nosotros centramos nuestro trabajo, también teníamos trabajo en bancarios pero esa actividad era una actividad clandestina muy fuerte.

En Salta, se contaba con un buen trabajo realizado en torno a obreros y la juventud de Metán. En Neuquén y en Comodoro Rivadavia, había establecido células entre los trabajadores petroleros y los de la construcción. Además, tenía agrupaciones de estudiantes universitarios y células en numerosos pueblos y ciudades pequeñas. En el Chaco y Formosa, contaba con una incipiente organización entre los judiciales, los empleados estatales y los trabajadores rurales. También en el norte, se había iniciado un embrionario trabajo entre las Ligas Agrarias, dirigidas principalmente por Montoneros, y había una pequeña estructura entre los trabajadores rurales de Misiones y Corrientes con vínculos en la dirección local de la Federación Argentina de Trabajadores Rurales y Estibadores (FATRE)

En todo lo anterior, debería quedar claro que el PRT-ERP no se desarrollaba en un vacío. El período fue de un crecimiento generalizado de toda la izquierda, por lo que era probable que se encontrara con competidores en cada lugar donde la organización desarrollaba un trabajo de masas. El mero hecho de que los obreros más conscientes y combativos tuvieran muchas opciones de militancia resalta aún más el logro que fue el 
desarrollo rápido y variado del PRT-ERP a nivel nacional. Sólo las agrupaciones ligadas a Montoneros tuvieron un desarrollo equiparable. A su vez, en la izquierda, el Partido Comunista tenía una presencia más amplia, pero que era el resultado de medio siglo de trabajo político. Así, en un lugar tan saturado de política como el movimiento obrero cordobés de principios de la década de 1970, el PRT-ERP logró uno de sus desarrollos más notables. ${ }^{16}$ De la información disponible, reseñada más arriba, se puede deducir que la inserción del PRT-ERP a través del país, entre 1972 y 1975, era muy variada.

Parte del problema era articular una línea política que uniera dialécticamente la lucha armada con el trabajo de masas. Las acciones del ERP durante el período prestigiaron a la organización, popularizaron su nombre, y le generaron simpatía entre la población. Pero este éxito no se tradujo en una línea que posibilitara una acumulación e inserción con facilidad. Dicha línea era contradictoria. Por ejemplo, en las resoluciones del V Congreso se planteaba que "nuestro partido debe alentar e impulsar la multiplicación de agrupaciones clasistas amplias, de comisiones de resistencia fabriles [... ] la defensa de la legalidad de los sindicatos y la lucha por su recuperación para la clase obrera”. Un año más tarde, en 1971, y antes de la desviación militarista, esto fue modificado por la orientación:

[...] La manera [...] de lograr una orientación firmemente antidictatorial en los sindicatos y movilizar tras ellos a las más amplias masas, es con la presencia y desarrollo de nuestro Partido, con la acción armada del ERP dentro de la fábrica y en relación con la lucha sindical, en la fundación de células de nuestro partido en las fábricas y otros lugares de trabajo y la incorporación creciente de obreros fabriles al ERP". ${ }^{17}$

El mismo documento veía la tarea partidaria en las fábricas como "la formación de unidades del ERP en las fábricas y la distribución de fuerzas, dando mayor importancia a este sector". A su vez, el folleto El Peronismo caracterizaba "la lucha armada y, en general, el uso de la violencia popular constituye la forma más alta de la lucha de

\footnotetext{
${ }^{16}$ Quizás uno de los aspectos más notables es que el PRT-ERP en Córdoba, donde tenía una fuerte competencia y oposición desde la misma izquierda, logró un desarrollo en extensión y profundidad mucho mayor que en lugares donde era casi la única opción revolucionaria.

${ }_{17}$ Resoluciones del Comité Central de marzo de 1971 (DE SANTIS, 1998, 203).
} 
clases". ${ }^{18} \mathrm{Y}$, en 1973 , se trataba de corregir la orientación, apuntando a una síntesis de ambas posiciones, planteando que se debía

[...] luchar por la independencia del movimiento sindical [...], impulsar y apoyar enérgicamente la lucha y movilización de los trabajadores por sus reivindicaciones inmediatas [...], promover un amplio frente antiburocrático legal $[\ldots]$, mantener y continuar desarrollando [...] la Tendencia Obrera Revolucionaria, de carácter clandestino, con un programa por la guerra y el socialismo, a nivel fabril $[\ldots] .{ }^{19}$

A pesar de lo contradictorio de la línea política (que daba lugar para que cada militante la interpretara a su manera), el PRT-ERP desarrolló, a partir de 1972, un importante trabajo de masas. Quizás en el lugar donde mejor se lograra ese trabajo haya sido Córdoba. Sin embargo, todos los testimonios coinciden en que el trabajo de masas era bastante contradictorio: el PRT lograba captar obreros y generar simpatía, pero no trascendía hacia una influencia política concreta. Si bien era la organización mayoritaria en cuanto a captación de voluntades, no era la principal organización que dirigía el sindicato. Aquí, parecería haber existido una inversión de un fenómeno tradicional en el sindicalismo de izquierda por el cual los obreros les otorgaban su apoyo sólo dentro de los límites de la fábrica. En el caso del PRT-ERP, los obreros que fueron captados por la organización parecen haberle otorgado su adhesión fuera de la fábrica, revelando problemas en su política sindical y el abismo entre la propuesta estratégica de la toma del poder para el socialismo a través de la lucha armada, y las reivindicaciones cotidianas de los trabajadores.

Claramente, el PRT-ERP había logrado una estructura importante y una inserción notable entre los trabajadores cordobeses. Esto se puede constatar más aún si consideramos desde datos puntuales hasta elementos más globales. Por ejemplo, según el responsable que atendía el frente sindical de Perkins, allí se vendían cien ejemplares de El Combatiente, o sea uno de cada doce obreros lo compraba. Al igual que en Luz y Fuerza, en Perkins la recepción era buena y el principal problema era dar respuesta a la

\footnotetext{
18 Julio Parra. El Peronismo. Ediciones El Combatiente, 1971 (DE SANTIS, 1998, 249).

${ }^{19}$ Resoluciones del Comité Ejecutivo de Abril de 1973 (DE SANTIS, 1998, 376-377).
} 
cantidad de inquietudes que se generaban. Otro ejemplo, ya en un nivel distinto, fue el papel del Movimiento Sindical de Base en la zona. El MSB, junto con Agustín Tosco y el Partido Comunista, fue instrumental en la conformación del Movimiento Sindical Cordobés que, entre 1974 y 1975, efectivamente lideró la actividad de la clase obrera cordobesa.

La existencia de una estructura, la captación de nuevos militantes o la simpatía de sectores de trabajadores no necesariamente significó que la inserción fuera muy profunda. Uno de los principales problemas era la inexperiencia política y del desconocimiento de la realidad regional por parte de los militantes. Sin embargo, también existía un problema que se vinculaba justamente con el "estilo partidario". Sus militantes eran referentes e inclusive muy queridos y apoyados. Sin embargo, la clandestinidad por un lado, y por otro la inexperiencia hacía difícil transformar este prestigio en una acumulación política duradera. De hecho, distintos vecinos testimoniantes expresaron su cariño, su apoyo y su admiración, sin embargo no ingresaron a la organización ni estaban del todo seguros qué planteaba. ${ }^{20}$

Un ejemplo es el padre Nelio Rougier, uno de los pocos sacerdotes que ingresaron al PRT-ERP. ${ }^{21}$ Muy querido por los habitantes de Barranca Yaco (Córdoba), perseguido por la represión, el padre Rougier fue enviado a integrar el ERP en el monte tucumano en 1975, donde fue muerto por el Ejército. Veinte años más tarde, varios de los vecinos entrevistados aseguraron que no estaba muerto y que regresaría a la villa algún día; mientras que otros insistían que las fuerzas de seguridad lo habían capturado y crucificado en una cruz invertida. A pesar de este aprecio, es notable que, según otro de los militantes de esta célula, el PRT-ERP no ganó ningún militante como resultado del

\footnotetext{
${ }^{20}$ Esto no fue sólo un problema del PRT-ERP. Casi todos los marxistas argentinos aceptaron que la clase obrera era uniformemente peronista y por ende virulentamente antimarxista. Por lo tanto, las prácticas políticas se desarrollaron a través de aproximaciones indirectas que evitaran una identificación abierta y directa como marxista. La experiencia de dirigentes gremiales, como Tosco o Salamanca, y la misma experiencia de Santucho, indican que esta apreciación estaba errada. Sin embargo, sólo podemos especular qué hubiera ocurrido en torno a la inserción de la izquierda y la politización de los trabajadores si se hubiera abordado el trabajo de masas desde una perspectiva abiertamente marxista.

${ }^{21}$ Los sacerdotes progresistas o izquierdistas tendían a ingresar en Montoneros donde sentían que no había contradicción entre su catolicismo y el peronismo revolucionario. Montoneros hasta tuvo un "capellán militar" reproduciendo la estructura del Ejército argentino. Sin embargo, sí hemos podido ubicar algunos sacerdotes católicos y varios protestantes que ingresaron al PRT-ERP.
} 
trabajo realizado en esta villa. He aquí un problema que se va a repetir: aun cuando la inserción fuera buena, el PRT-ERP tenía problemas para traducirla en una acumulación política duradera. Quizás gran parte del problema estribó en que el trabajo de masas del PRT-ERP se basaba principalmente en lo reivindicativo. En este sentido, no tenía diferencias significativas con el del resto de la izquierda, incluyendo a la no armada. Donde sí se diferenciaba era en el estilo y en cuanto a que entroncaba con el accionar armado de la organización. La originalidad, entonces, residió en las formas de contactar con la gente y en la energía y creatividad con que se llevó adelante el trabajo de masas, pero, al mismo tiempo, la organización no supo vincular este trabajo con un cuestionamiento duradero del sistema socio-económico imperante. ${ }^{22}$

El ejemplo anterior contrasta con otros donde la inserción si se tradujo en acumulación política, pero donde también se revelan las virtudes y los problemas del PRTERP para insertarse. Dos de estos casos fueron los del pueblo azucarero de San José (Tucumán) y el barrio de Villa Libertador (Córdoba). En el primer caso, varios de los vecinos entrevistados se referían a los guerrilleros del PRT-ERP como “diferentes", pero parte integral de la comunidad, a diferencia de las fuerzas de seguridad que eran consideradas “extraños”. En el caso de Villa Libertador, la gente recuerda el período de organización guerrillera como una de las mejores épocas para la comunidad, cuando pudieron realizar una cantidad de cosas, y cuando la policía se cuidaba de molestarlos demasiado. ${ }^{23}$ De hecho, el PRT-ERP organizó a partir del dispensario local, pudiendo ganar varios vecinos para la organización. Inclusive, después de la caída del principal militante del trabajo en la zona, la organización logró retener una inserción hasta las vísperas del golpe de estado de $1976 .{ }^{24}$

\footnotetext{
${ }^{22}$ Lo complejo de este problema se puede visualizar si tomamos en cuenta que distintos sectores (obreros, villeros, barriales) se acercaron a la izquierda debido a problemas concretos que el Estado no podía o no deseaba resolver. La contradicción entre necesidades e intereses inmediatos y las relaciones de poder del capitalismo se hacían evidentes, generando una incipiente politización. La izquierda y/o el peronismo revolucionario organizaban a la gente y resolvían el problema. Al resolverlo, dentro de los marcos del sistema imperante, eliminaban las causas inmediatas del cuestionamiento popular. El problema se convertía en cómo generar un fortalecimiento de la conciencia antisistémica en el proceso de contactar a los trabajadores a través del accionar reivindicativo.

${ }^{23}$ El PRT-ERP no fue la única organización política en Villa Libertador. También organizaban en la zona Vanguardia Comunista y los Montoneros. Estos últimos basaron su trabajo en la parroquia y en uno de los médicos del dispensario que se había establecido conjuntamente con los militantes del ERP.

${ }^{24} \mathrm{El}$ médico fue muerto en un accidente de ruta después de haber participado del copamiento de la Fábrica
} 
Otro ejemplo de la inserción lograda a través de un buen trabajo de masas es el caso de Villa Gobernador Gálvez, en las afueras de Rosario. Gálvez contiene una fuerte concentración obrera, particularmente de la carne y metalúrgicos, que históricamente ha sido peronista. Pero, al mismo tiempo, fue un lugar donde el PRT-ERP logró desarrollar un trabajo de masas importante que sobrevivió bastante tiempo después de la destrucción de la organización en el nivel nacional. En este caso, los testimoniantes si identificaban claramente a la organización política a la que pertenecían los militantes. Esto implica una identificación muy fuerte con los militantes. En este sentido, la inserción lograda fue muy fuerte, hasta el punto que el cariño y la simpatía llevan a un inconsciente acercarse al grupo militante. Esto también implica que no todos los vecinos tenían la misma actitud, si bien aclaran que la simpatía por los guerrilleros era generalizada. Por último, es de remarcar el porqué no buscaron el ingreso a la organización. La impresión es que tenían un alto concepto del PRT-ERP y de su misión revolucionaria, pero no se sentían a la altura: era para gente “especial”. Por otro lado, también surge la cuestión de si la solidaridad expresada implicaba un compartir la línea política de los militantes. En el testimonio, queda claro que los militantes de la zona tenían un apoyo bastante profundo de los vecinos de Villa Gobernador Gálvez. La pregunta que queda pendiente es si no lo hubiera tenido cualquier otro militante popular, con similares cualidades humanas, más allá de ser o no del PRT-ERP.

Al igual que en el caso de Barranca Yaco y de Villa Libertador, en todos los testimonios se repite el tema del miedo a la represión. La diferencia es que en el caso de Gálvez, el trabajo del PRT-ERP había logrado una inserción profunda como para que la gente protegiera a los militantes a pesar de la intensidad de la represión. Lo que va, finalmente, a destruir esta inserción no va a ser tanto la represión en la zona como la destrucción de la organización guerrillera a nivel nacional. Por otro lado, es notable como, en una zona obrera y fuertemente peronista, el PRT-ERP logró tener una presencia importantísima, casi excluyente de otras organizaciones armadas. Por ejemplo, según distintos testimonios, los Montoneros nunca lograron hacer pie en la zona más allá de dos unidades básicas, "pero con estudiantes que traía para atenderlas". En cambio, las vecinales en general las controlaba el PRT-ERP, a través de una fuerte presencia en las 
comisiones directivas. Esta presencia vecinal se articulaba dialécticamente con la fuerza del PRT-ERP en los frigoríficos (particularmente Swift, Sugarosa y Paladini) y en las fábricas metalúrgicas de la zona. De hecho, la agrupación sindical de la carne "El Toro", que contaba con unos 150 activistas, estaba orientada por los militantes de la organización guerrillera. Según uno de estos activistas, la razón de esta inserción era

[... ] que el PRT tenía [...] un mensaje simple, que la gente entendía, que es 'acá están los pobres y acá están los ricos'. Creo que ese mensaje era muy simple para la gente. Toda esta zona tenía mucho laburo del PRT. Cada dos casas había algún contacto. ${ }^{25}$

Evidentemente, la inserción de una organización era una cosa por demás compleja, puesto que había que articular la política con los sentimientos; al decir de los vietnamitas (muy citados por el PRT-ERP) había que ganar el corazón y la mente de la gente. Esta tarea requería no sólo experiencia, sino también una calidad especial del militante. En aquellos lugares donde los militantes del PRT consiguieron articular los distintos niveles, se logró una importante inserción de la organización. La inserción se hacía a veces, inclusive, en contra de la práctica de los propios compañeros de organización. El ganar el corazón y la mente de los trabajadores implicaba una calidad del militante en cuanto a lo humano, pero también una claridad en términos de combinar formas de lucha y en cuanto a no confundir combatividad con conciencia. Al mismo tiempo, hubo un problema permanente en cuanto a la tendencia a substituir la actividad de las masas con el accionar del ERP. No sólo la inserción podía ser débil, sino que inclusive la actividad militar podía generar el rechazo de la gente. Esto último deja sin responder una serie de preguntas de fondo en torno al desarrollo de la conciencia del pueblo argentino y su relación con la actividad para un cambio revolucionario, y respecto de si los métodos empleados eran los más adecuados a los objetivos planteados.

Por otro lado los mismos documentos internos de la organización señalan sus prioridades en cuanto a la distribución de cuadros y los problemas que de esto se podían derivar. A principios de 1975, el PRT-ERP distribuyó una recomendación para las

\footnotetext{
${ }^{25}$ Lo que se entiende por "mensajes simples" tiene mucho que ver con el estilo partidario del PRT-ERP y es una de las claves para comprender lo rápido de la extensión de su inserción con una profundidad muy desigual.
} 
direcciones zonales y regionales, "con el fin de mantener un desarrollo armónico", definiendo "el siguiente porcentaje aproximado de distribución de los compañeros por tipo de tareas: Militar 30\%, Sindical 15\%, Propaganda 15\%, Estudiantil 15\%, Legal 10\%, Organización (Dirección) 10\%, Juventud 5\%”. ${ }^{26}$ Lo primero que se debería destacar es que la mayoría de los militantes no estaban asignados a tareas militares. Pero, al mismo tiempo, es notable que se recomendaba que sólo el $45 \%$ del total estuvieran asignados a trabajos de masas (Sindical, Estudiantil, Legal y Juventud), mientras que tareas de aparatos (Propaganda y Organización) absorbían 25\% del activo. Pero es aún más notable, para un partido que se reivindicaba del proletariado, que no se establecieran criterios políticos para esta distribución que equipara en importancia la tarea con la clase obrera (Sindical) con la estudiantil, y ambas con Propaganda. Por un lado, se declamaba la prioridad del trabajo político en la clase obrera; por otro, esto se contradecía con la distribución de los cuadros.

Aquí, hay que considerar, brevemente, algunos problemas más de fondo en términos del trabajo de masas del PRT-ERP, teniendo en cuenta tres niveles. El primero es el del militante. En este nivel, la juventud e inexperiencia de muchos, junto con la tradición de la izquierda, hizo que se confundiera combatividad con conciencia y simpatía con compromiso. Enfrentados por la represión, sectores que demostraban su simpatía, o que eran casi irreflexivamente combativos, se retrajeron dejando a los activistas sin el apoyo social que les permitiera continuar con su labor. Ahora bien, ¿por qué la organización, y no sólo el militante individual, no visualizó esto? Aquí reside en gran parte la debilidad de la dirección del PRT-ERP. Si bien la línea política de la organización planteaba que había que escuchar a las masas, la realidad era muy distinta. La visión de sí misma que tenía la dirección del PRT, el concepto de que el partido representaba la ideología del proletariado, la tradición cuasi positivista de que la organización no podía equivocarse, el concepto de la lucha de clases en el seno del partido, todo se unían para que la dirección casi no escuchase a las bases y por ende que las críticas y sentires de las masas no fueran auscultados o entendidos. Una dirección política puede llevar adelante su tarea con éxito en la medida en que permite que la base sea una correa de transmisión

\footnotetext{
${ }^{26}$ Boletín Interno, 76, 22 de febrero de 1975.
} 

sus miembros. Lo sorprendente del PRT-ERP es que hubiera logrado una buena inserción en muchos de los lugares donde se lo propuso, a pesar de carecer de militantes con experiencia en el trabajo de masas.

El segundo nivel fue la represión misma. Esta se centró en los nexos entre el PRT y las masas. Delegados gremiales, activistas barriales, dirigentes estudiantiles fueron los blancos preferidos de la represión. Por ejemplo, para eliminar el peso del PRT en el estudiantado tucumano, las "fuerzas del orden" dinamitaron el comedor universitario. Esto quitó un lugar de reunión y de concentración, dificultando los nexos entre el activo y distintos sectores de masas.

Por último, hay que considerar un problema serio en términos de lograr una buena inserción. El PRT-ERP, en 1968, era una organización pequeña. En este sentido, enviaba a sus mejores cuadros a abrir trabajos en distintas zonas. Esto resultaba en que las direcciones zonales pocas veces correspondían a cuadros de la misma zona, lo que generaba dificultades y problemas con los militantes locales, trababa su formación y ascenso e impedía que una dirección regional tuviera un profundo conocimiento del área. Por ejemplo, en Mendoza, en 1975, la mayoría de la dirección regional era de Córdoba. Esta permanente rotación de cuadros impedía que ninguno se asentara, desarrollara un trabajo a largo plazo, y consolidara el existente. En aquellos lugares donde no fue así, como en Córdoba o Rosario, y más tarde Buenos Aires, la profundidad y calidad del trabajo de masas fue notable.

Lo que se puede percibir es que si bien la labor del PRT dejó una cierta sensación de simpatía, su aporte a la politización del conjunto del pueblo argentino encontró límites concretos en cuanto a que nunca fue lo suficiente como para dar el salto cualitativo que implica un cuestionamiento profundo del sistema de relaciones socio-económicas imperantes. Excepto en Tucumán y en Gálvez, muchos vecinos no recuerdan con claridad a qué organización pertenecían los guerrilleros de la zona, y rara vez hicieron referencia a cambios más profundos: aun cuando expresaban su admiración lo hacían usando la 
terminología oficial y resignificándola al hablar de "subversivos" o de "terroristas". Es notable que, veinte años más tarde, estos vecinos no recuerden haber tenido miedo de la guerrilla, aunque sí de la represión. Todos expresaban miedo a la violencia, una falta de comprensión de la política de la guerrilla, y distintas formas de simpatía ("tenían buenas intenciones"; "finalmente alguien se puso de pie”; “eran arriesgados”; “ojalá los hubiera ayudado en ese entonces"). En algunos casos, hasta dijeron recordar que la guerrilla ayudaba y protegía a la comunidad de las fuerzas de seguridad. Claramente, estos recuerdos expresan que el fenómeno guerrillero ha sido reinterpretado en la memoria. Sin embargo, esto no significa que los sentires expresados sean una invención, producto exclusivamente del presente. Mucho más probable es que esta memoria se base en sentires de este entonces. Esto significa que el grado de inserción logrado por el PRT-ERP fue notable y amplio, puesto que ha logrado marcar la memoria popular. Pero, al mismo tiempo, no fue demasiado profundo, puesto que esta misma memoria vincula la guerrilla a lo reivindicativo y rara vez da el salto hacia lo político.

\section{Entrevistas}

Fueron entrevistados 88 antiguos militantes del PRT-ERP y 20 vecinos en zonas donde la organización desarrolló su tarea. Las entrevistas a los militantes tuvieron el formato de "historia de vida", con repregunta. Las entrevistas a los vecinos fueron temáticas, apuntando a evocar la memoria y disparar la subjetividad. Los nombres de los entrevistados no se publican particularmente para preservar su seguridad.

\section{Referencias}

DEBRAY, Regis. Revolution in the Revolution? New York: The Grove Press, 1967.

DE SANTIS, Daniel (selección). A Vencer o Morir. PRT-ERP Documentos. Buenos Aires: Eudeba, 1998.

MATTINI, Luis. Hombres y mujeres del PRT-ERP. Buenos Aires: Editorial Contrapunto, 1990.

PRT-ERP. Anteproyecto de resolución sobre internacional, In: Hacia el VI Congreso 1974. Mimeo.

SANTUCHO, Roberto Mario [sic]. Poder burgués y poder revolucionario. , 23 de agosto de 1974 . 
Recebido em 09/07/2015 Aprovado em 09/09/2015

Universidade do Estado de Santa Catarina - UDESC

Programa de Pós-Graduação em História - PPGH

Revista Tempo e Argumento Volume 07 - Número 16 - Ano 2015 tempoeargumento@gmail.com 